oversewing of the ulcer) was employed in a minority of cases. As time went by vagotomy plus drainage came to be used more and more, and this procedure was performed in $75 \%$ of the emergency operations in which one of these three procedures was used.

Vagotomy plus drainage has emerged as more successful than a partial gastrectomy. Among patients aged less than 60 the fatality rate was low and there was no great difference between vagotomy and partial gastrectomy; but among patients aged 60 and over the surgical fatality rate was considerable and the results with vagotomy were decisively better than with either type of partial gastrectomy.

As medical treatment remained essentially unaltered throughout the period studied, and as surgical practice showed a clear advance due to the increasing use of vagotomy plus drainage, it is at first sight paradoxical that no improvement in the overall fatality rate occurred. The explanation appears to be simple. During the period studied a diminishing proportion of patients were treated by emergency surgery. Thus the improved results of surgery were counterbalanced by the failure to perform emergency operations on as many patients in the last quinquennium as in the first.

For the future there appears to be a prima facie case for the more frequent use of emergency surgery in the management of haematemesis and melaena. There are a number of clinical features at the time of the patient's admission to hospital which have a bearing on prognosis and could be used as indications for early surgery. To what extent attempts at early precise diagnosis of the underlying cause of the bleeding will influence prognosis must remain problematical. To date, the increasing use of emergency barium meal examinations has had no beneficial effect on the outcome, but this may have been due to a failure to proceed to early surgery in spite of earlier diagnosis of focal lesions. Endoscopy remains to be fully exploited. The main question is whether emergency surgery should be practised as soon as possible after admission in patients shown to have a focal lesion and with some attributes suggesting the possibility of a poor prognosis if handled along traditional lines. In other words, is it better to operate preventively than to wait for further heavy bleeding to occur?

In this connexion it is highly pertinent that in the present series four out of every five patients who died did so after they had been in hospital more than two days. So far as those dying without surgery are concerned the figure was three out of every four. If bleeding oesophageal varices are excluded, because these are likely to be dangerous however they are treated, four out of every five medical deaths occurred more than two days after admission. Among patients with gastric or duodenal ulcer no fewer than seven out of every eight medical deaths occurred more than two days after admission. It is plain that there was ample time for emergency surgery to be carried out on most of the patients who died without being treated surgically.

While these conclusions are based solely on the experiences of the Radcliffe Infirmary, we consider that many of our findings are applicable to many other hospitals employing traditional methods in the treatment of acute upper gastrointestinal bleeding. The problem is a large and important one. As the Radcliffe Infirmary deals with a population of 300,000 , an annual admission rate of 140 patients with haematemesis or melaena implies that there are about 28,000 emergency admissions each year for the whole country. If our fatality rate of $8.9 \%$ is taken as representative, this means that there are about 2,500 deaths in hospital each year from this cause. In a large proportion the underlying cause is a benign focal lesion. In view of the great efforts that are being made to reduce the fatality rate in other common and dangerous conditions, such as myocardial infarction, it seems strange that comparatively little attention is paid to improving the methods of managing severe haematemesis and melaena.

We are indebted to the Nuffield Committee for a research grant to one of us (K.F.R.S.). We wish to thank Mrs. M. Witts, Miss Anne Leech, Mrs. N. Nott, Miss M. McLarty, Miss Patricia Morrison, and Miss Carol Sharman for their assistance in various ways.

\title{
Relationship between Breathlessness and Anxiety in Asthma and Bronchitis: A Comparative Study
}

\author{
N. C. OSWALD,* T.D., M.D., F.R.C.P.; R. E. WALLER, † B.SC.; J. DRINKWATER, $\ddagger$ B.SC., DIP.PSYCH.
}

British Medical fournal, 1970, 2, 14-17

\begin{abstract}
Summary: Two personality testing forms, the Eysenck $S$ Personality Inventory Form $A$ and the Cattell Self Analysis Form, were completed on 471 hospital patients who fell within the general diagnostic range of asthma, bronchitis, or both. Respiratory diagnoses were based on the standard M.R.C. questionary. All categories of patients showed a tendency towards neuroticism, anxiety, and introversion, and the scores were slightly higher for bronchitics than for asthmatics. Neuroticism and anxiety increased with increasing respiratory disability. Variations in these scores with age of onset of symptoms and length of history were small.
\end{abstract}

\section{Introduction}

Personality testing by means of questionaries is now an accepted method of psychological investigation. The Eysenck Personality Inventory Form A (Eysenck and Eysenck, 1964) and Cattell's Self Analysis Form (Cattell and Scheier, 1963), the

\footnotetext{
* Consultant Physician.

† M.R.C. Scien

St. Bartholomew's Hospital, London E.C.1.
}

one English and the other American, have now been completed on many thousands of subjects, principally in psychiatric units and educational establishments. The Eysenck. Personality Inventory Form A aims to measure neuroticism and introversion-extraversion, and Cattell's Self Analysis Form total anxiety and its components. Each, as a result of laborious experiment, is now regarded as giving a reasonably accurate assessment of these measurements. So far, they have been little used for general medical purposes, except in small series of patients. The opportunity has been taken of applying them to a large group of hospital patients who fell within the general diagnostic range of asthma and bronchitis. The clinical grading was based on answers to the Medical Research Council (1966) questionary on respiratory symptoms, to which some questions specifically relating to asthma were added.

The purpose of the study was to determine whether these personality traits were especially associated with asthma or bronchitis or with some component of either. The question of using other hospital patients as controls was considered, but difficulties were encountered in deciding which patients had similar degrees of disability and whether patients suffering from non-pulmonary diseases could be included. In the event, it was decided that the comparison should be between 
asthmatic and bronchitic patients, the figures obtained being then related to the accepted normal values for the general population.

\section{Definitions}

\section{Psychological Assessment}

The Eysenck Personality Inventory Form $A$ is a 57 -item questionary containing neuroticism (N.) and extraversionintroversion (E.) scales, having 24 questions devoted to each. There is also a short scale of nine questions assessing the subject's probable honesty in reporting his behaviour, the lie scale. Neuroticism refers to a person's tendencies towards emotional instability and over responsiveness and to his liability to abnormal reactions to stress. Extraversion indicates tendencies to be outgoing, uninhibited, and gregarious; introversion is the converse. Scores on the $N$. and E. scales have been shown to be relatively independent of each other. The normal mean $\mathrm{N}$. score is 9.1 , the $\mathrm{E}$. score 12.1 , and the lie score 2.3. A high $\mathbf{N}$. score indicates neuroticism, a high $\mathbf{E}$. score extraversion, and a high lie score unreliability in completing the form.

Anxiety may be defined as an emotional state having increased alertness and responsiveness to stimuli, with various bodily manifestations arising from autonomic dysfunction. Cattell's Self Analysis Form is a 40-item questionary which assesses anxiety, whether determined by the immediate situation or not. It comprises five subscales which refer to possible sources of anxiety-for example, guilt feelings, social insecurity. The score for the total and each subscale is graded from 1 to 10 , the standard 10 abbreviated to sten, and is referred to as the (total) sten score or subscale sten score. A sten score of 1 to 3 indicates a phlegmatic, placid personality; 4 to 7 an average degree of anxiety; and 8 to 10 an unusually high anxiety level "almost certain to have adverse effects generally upon work and socio-emotional adjustment." The normal mean score is 5.5. Cattell's Self Analysis Form is also divided into a section covering anxiety of which the patient is aware and to which he will admit (overt anxiety or B score) and a section containing items whose relation to anxiety is relatively indirect and hidden (covert anxiety or A score). Covert (A) and overt (B) scores are usually expressed as a ratio.

\section{Diagnostic Categories by Respiratory Symptoms}

Though all the patients in this study gave some history of asthma and/or bronchitis, the diagnostic categories adopted in the analysis of the results were based strictly on respiratory symptoms (Medical Research Council, 1966) as follows:

B. (Bronchitis). Cough and phlegm on most days for as much as three months each year ("yes" to Q.5 and Q.10). In addition these patients either had no attacks of shortness of breath with wheezing ("no" to Q.16a) or their breathing was not absolutely normal between such attacks ("no" to Q.16b).

A. (Asthma). Attacks of shortness of breath with wheezing, with absolutely normal breathing between attacks ("yes" to Q.16b).

B.A. (Broschitis and asthma). Cough and phlegm as indicated for bronchitis and attacks of asthma.

O. (Others). These did not meet the exact requiresacnts of B. or A.: many had persistent cough but not persistent phlegm.

Routine radiographs of the chest were available for all the patients and served to eliminate those who had other significant respiratory disease.

\section{Material}

The inquiry began in October 1967 and ended in March 1968. Blocks of questionaries were completed on consecutive bronchitic and asthmatic patients seen at seven centres. $\int$ It was limited to patients within the age range of $20-60$ years in order to eliminate difficulties in interpreting anxiety ratings in the young and elderly (Cattell and Scheier, 1963). Both inpatients and outpatients were included. Altogether, data were collected on 471 patients ( 275 men and 196 women).

The group as a whole showed most of the features to be expected in patients with established respiratory disease. The excess of men was in the bronchitis category (Table I). The

TABLE I.-Distribution of 471 Patients by Diagnostic Category

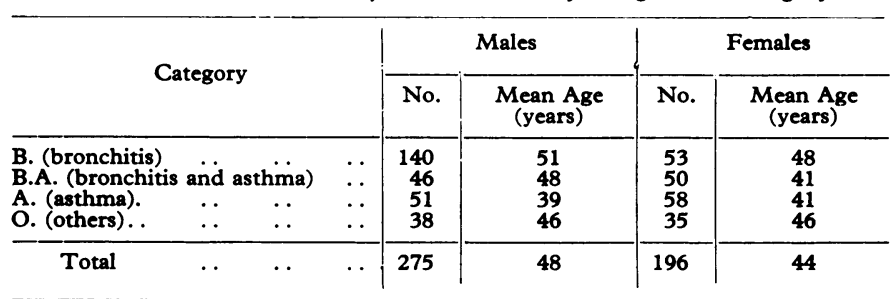

average age of the bronchitic patients was higher than that of the asthmatics. Compared with the general population, there was a deficiency of lower social class patients (General Register Office, 1961) even within the bronchitis group, and this reflected the type of patients attending the hospitals in the study. Differences in the distribution of civil state, height, and weight by diagnostic category were not significant, but there was a tendency for the group with asthma only to include more single people and for them to be a little taller and heavier than the others. Smoking habits did not differ greatly from those of the general population (Todd, 1966), but there was a slight excess of cigarette smokers among the bronchitic patients.

Peak flow was measured on every patient, the results being reported as the mean value of the last three of a set of five readings. The range was very large, from under 100 to nearly 600 litres/minute, but within each diagnostic category the values were on average only about one-half of those predicted from the tables quoted by Cotes (1968). These figures confirm that most patients were moderately or severely disabled. Peak flow, when correlated with the subjective assessment of disability based on breathlessness (Table II), was low even among patients who did not report any breathlessness, and it declined steadily with increasing disability.

TABle II.-Peak Flow (Percentage of Predicted value) in Relation to Breathlessness

\begin{tabular}{|c|c|c|c|}
\hline Breathlessness Grade & & & $\begin{array}{l}\text { Peak Flow. } \\
\% \text { Predicted }\end{array}$ \\
\hline 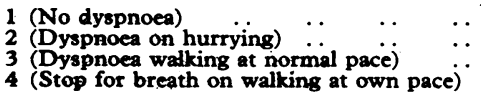 & $\begin{array}{ll}\because & \cdots \\
\cdots & \cdots \\
\cdots & \end{array}$ & $\begin{array}{l}\cdots \\
\because \\
\cdots\end{array}$ & $\begin{array}{l}56 \\
51 \\
41 \\
34\end{array}$ \\
\hline
\end{tabular}

The breathiessness grades relate to question 14 of the Medical Research Council (1966)

questionary. Pex, and beight.

\section{Results}

Two-way tables were prepared showing the distribution of personality scores by diagnostic category. Men and women were considered separately, and $\chi^{2}$ goodness of fit tests were applied to each table to test the hypothesis that there was no difference in distribution of the scores between the four categories. In all cases the value of $\chi^{2}$ was below that for the $5 \%$ level of significance. Thus there was no meaningful dif-

$\S$ Brompton Hospital, St. Bartholomew's Hospital, Royal Berkshire Hospital, Southend Chest Clinic, Maidstone Chest Clinic, Leeds Chest Clinic, and King Edward VII Hospital, Midhurst. 
ference in these personality scores between the diagnostic categories. They were, however, perceptibly different from those of the normal populations. Table III shows the means and standard deviations for the N., E., lie, and sten scores compared with the corresponding figures for normals.

TABLE III.-Personality Scores by Diagnostic Categories

\begin{tabular}{|c|c|c|c|c|c|c|c|c|c|}
\hline \multirow{3}{*}{ Category } & \multirow{3}{*}{ Sex } & \multicolumn{6}{|c|}{ E.P.I. Scores } & \multirow{2}{*}{\multicolumn{2}{|c|}{$\frac{\begin{array}{c}\text { C.S.A.F. } \\
\text { Score }\end{array}}{\text { Sten }}$}} \\
\hline & & \multicolumn{2}{|c|}{ N. } & \multicolumn{2}{|c|}{ E. } & \multicolumn{2}{|c|}{ Lie } & & \\
\hline & & Mean & S.D. & Mean & S.D. & Mean & S.D. & Mean & S.D. \\
\hline B. & $\begin{array}{l}\text { M. } \\
\text { F. }\end{array}$ & $\begin{array}{l}12 \cdot 0 \\
13 \cdot 1\end{array}$ & $\begin{array}{l}5 \cdot 2 \\
5 \cdot 4\end{array}$ & $\begin{array}{l}10.2 \\
10.9\end{array}$ & $\begin{array}{l}4 \cdot 2 \\
4 \cdot 3\end{array}$ & $\begin{array}{l}3.8 \\
3.9\end{array}$ & $\begin{array}{l}2 \cdot 0 \\
2 \cdot 0\end{array}$ & $\begin{array}{l}7 \cdot 0 \\
6 \cdot 7\end{array}$ & $\begin{array}{l}1.9 \\
2.0\end{array}$ \\
\hline B.A. & $\underset{\text { F. }}{\text { M. }}$ & $\begin{array}{l}11 \cdot 1 \\
13.5\end{array}$ & $\begin{array}{l}5 \cdot 1 \\
5 \cdot 2\end{array}$ & $\begin{array}{l}11 \cdot 1 \\
10 \cdot 6\end{array}$ & $\begin{array}{l}5 \cdot 0 \\
4 \cdot 2\end{array}$ & $\begin{array}{l}3.6 \\
4.0\end{array}$ & $\begin{array}{l}1.7 \\
1.5\end{array}$ & $\begin{array}{l}6.4 \\
6.7\end{array}$ & $\begin{array}{l}2.1 \\
1.9\end{array}$ \\
\hline A. & $\begin{array}{l}\text { M. } \\
\text { F. }\end{array}$ & $\begin{array}{r}9 \cdot 9 \\
12 \cdot 2\end{array}$ & $\begin{array}{l}5 \cdot 6 \\
5 \cdot 2\end{array}$ & $\begin{array}{l}12 \cdot 2 \\
11 \cdot 5\end{array}$ & $\begin{array}{l}4 \cdot 2 \\
4.9\end{array}$ & $\begin{array}{l}3 \cdot 1 \\
3 \cdot 7\end{array}$ & $\begin{array}{l}1 \cdot 8 \\
2 \cdot 0\end{array}$ & $\begin{array}{l}6 \cdot 2 \\
6 \cdot 3\end{array}$ & $\begin{array}{l}2 \cdot 0 \\
2 \cdot 1\end{array}$ \\
\hline o. & $\begin{array}{l}\text { M. } \\
\text { F. }\end{array}$ & $\begin{array}{r}9 \cdot 9 \\
12 \cdot 0\end{array}$ & $\begin{array}{l}5 \cdot 7 \\
3 \cdot 8\end{array}$ & $\begin{array}{l}10 \cdot 6 \\
11 \cdot 7\end{array}$ & $\begin{array}{l}3 \cdot 9 \\
4 \cdot 1\end{array}$ & $\begin{array}{l}4 \cdot 2 \\
4 \cdot 0\end{array}$ & $\begin{array}{l}2 \cdot 0 \\
1 \cdot 4\end{array}$ & $\begin{array}{l}5.9 \\
5.8\end{array}$ & $\begin{array}{l}2 \cdot 1 \\
2 \cdot 1\end{array}$ \\
\hline Normals & $M$. and F. & $9 \cdot 1$ & $4 \cdot 8$ & $12 \cdot 1$ & $4 \cdot 4$ & $2 \cdot 3$ & 1.6 & $5 \cdot 5$ & $2 \cdot 0$ \\
\hline
\end{tabular}

Normal population scores are quoted from the handbooks for the two questionaries Eysenck and Eysenck, 1964 ; Cattell and Scheier, 1963). deviation.

In each category the mean $\mathrm{N}$. and sten scores were higher than expected among normals. The women also had higher $\mathrm{N}$. scores than the men, as they do in normal populations (Eysenck and Eysenck, 1964). Interestingly, the bronchitic patients (B.) in this study had, on average, higher $\mathrm{N}$. and sten scores than the asthmatics (A.). E. scores were lower than normal in nearly all categories. Indeed this overall tendency towards neuroticism, anxiety, and introversion is to be expected in a group of patients most of whom were suffering from a moderate or severe physical disability.

The standard deviations of all the scores were close to the figures quoted for normal populations. High N. scores $(\geqslant 17)$ were found in $24 \%$ of groups B. and B.A. compared with $20 \%$ of group A. and $14 \%$ of group $O$. The proportions with low E. scores $(\leqslant 7)$ followed a similar pattern. There was also an excess of high sten scores $(\geqslant 8)$ among group B., and this group evidently lies a little nearer to the extreme ends of the neuroticism, anxiety, and introversion scales than the rest of the patients.

The mean lie scores were higher than those found in normals, and, perhaps surprisingly, they were highest in group $O$., the one with least symptoms. The proportion having high scores $(\geqslant 5)$, in the range where answers to the questionary may become unreliable, was similar in each group and amounted to $30 \%$ overall.

The personality scores appeared to be more closely related to breathlessness than to the diagnostic categories based on cough, phlegm, and wheezing. Table IV shows consistent trends in $\mathrm{N}$. and sten, the scores increasing with the severity of the breathlessness. There is also a tendency among the men (but not among the women) for $\mathrm{E}$. to decline with increasing breathlessness.

TABLE IV.-Personality Scores in Relation to Breathlessness

\begin{tabular}{|c|c|c|c|c|c|}
\hline \multirow{2}{*}{\multicolumn{2}{|c|}{$\begin{array}{l}\text { Breathlessness } \\
\text { Grade }\end{array}$}} & \multirow{2}{*}{ Sex } & \multicolumn{3}{|c|}{ Mean Scores } \\
\hline & & & N. & E. & Sten \\
\hline 1 & $\ldots$ & $\stackrel{\text { M. }}{\mathrm{F}}$ & $\begin{array}{l}10.2 \\
11.6\end{array}$ & $\begin{array}{l}12.3 \\
10.7\end{array}$ & $\begin{array}{l}6.3 \\
6.0\end{array}$ \\
\hline 2 & . & $\begin{array}{c}\text { M. } \\
\text { F. }\end{array}$ & $\begin{array}{l}10 \cdot 7 \\
12 \cdot 2\end{array}$ & $\begin{array}{l}10.9 \\
11.4\end{array}$ & $\begin{array}{l}6.5 \\
6.3\end{array}$ \\
\hline 3 & . & $\underset{\mathrm{F}}{\mathrm{M}}$. & $\begin{array}{l}11.8 \\
13.4\end{array}$ & $\begin{array}{r}9 \cdot 8 \\
12 \cdot 4\end{array}$ & $\begin{array}{l}6.6 \\
6.8\end{array}$ \\
\hline 4 & $\ldots$ & M. & $\begin{array}{l}12.4 \\
14.3\end{array}$ & $\begin{array}{r}9 \cdot 9 \\
10 \cdot 1\end{array}$ & $\begin{array}{l}7 \cdot 0 \\
6.8\end{array}$ \\
\hline
\end{tabular}

The breathlessness grades are as shown in Table II.
Similar relationships between personality scores and the degree of respiratory disability were found when using an objective assessment based on peak flow. To allow for differences in age and height, peak flow results were expressed as percentages of the values predicted for normals; the figures for men and women could then also be combined, and Table $\mathrm{V}$ again shows a trend towards greater neuroticism and anxiety with increasing disability. These findings are in keeping with clinical experience.

Table V.-Personality Scores in Relation to Predicted Peak Flow (Males and Females)

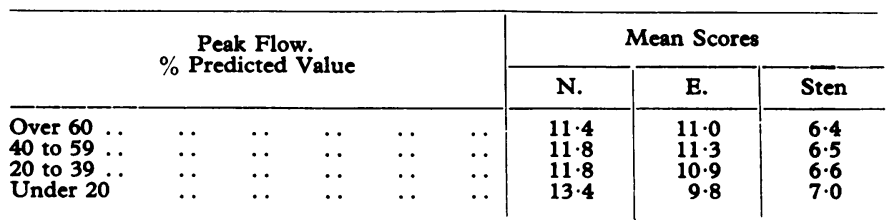

The results were examined in relation to many other characteristics that had been recorded in the survey. Study of Cattell's subscales and the overt-covert ratio showed no discernible differences between diagnostic categories. The variation with social class was examined, but there was no consistent trend in any of the personality scores with social class (General Register Office, 1961).

Results from asthmatic patients who had been investigated by skin tests were considered separately (Table VI). Those who reported positive reactions (to any or all of the common allergens tested) had slightly lower $\mathbf{N}$. and sten scores and higher E. scores than negative reactors, but these differences were not significant.

TABLE VI.-Personality Scores in Relation to Results of Skin Tests (Males and Females)

\begin{tabular}{|c|c|c|c|c|c|c|c|}
\hline \multirow{2}{*}{\multicolumn{4}{|c|}{$\begin{array}{l}\text { Results } \\
\text { of Skin Test }\end{array}$}} & \multirow{3}{*}{$\begin{array}{c}\begin{array}{c}\text { No. of } \\
\text { Patients }\end{array} \\
\begin{array}{c}145 \\
158\end{array}\end{array}$} & \multicolumn{3}{|c|}{ Mean Scores } \\
\hline & & & & & \multirow{2}{*}{$\begin{array}{c}\text { N. } \\
12 \cdot 0 \\
12 \cdot 4\end{array}$} & \multirow{2}{*}{$\begin{array}{c}\text { E. } \\
11 \cdot 7 \\
10.8\end{array}$} & \multirow{2}{*}{$\begin{array}{c}\text { Sten } \\
6.4 \\
6.7\end{array}$} \\
\hline $\begin{array}{l}\text { Positive } \\
\text { Negative }\end{array}$ & $\because$ & $\ldots$ & 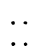 & & & & \\
\hline
\end{tabular}

The possibility that symptoms dating from childhood or extending over many years might be especially associated with a rise in the scores for neuroticism or anxiety was considered. With the numbers available it was not possible to divide the figures into small ranges of age or duration, but Table VII shows that patients reporting symptoms dating from childhood or early adult ages had slightly higher $\mathrm{N}$. and sten scores than the others, as did those with symptoms extending back over at least five years. Introversion tended to be associated with symptoms of late onset or extending over at least five years. These differences were not statistically significant.

TABLE VII.-Personality Scores in Relation to Onset and Duration of Symptoms

\begin{tabular}{|c|c|c|c|c|c|c|}
\hline & & & \multirow{2}{*}{$\begin{array}{c}\text { No. of } \\
\text { Patients }\end{array}$} & \multicolumn{3}{|c|}{ Mean Scores } \\
\hline & & & & N. & E. & Sten \\
\hline $\begin{array}{c}\text { Age at onset: } \\
0-9 \text { years } \\
10-29 \text { " } \\
30+\ldots \text { Duration: " }\end{array}$ & $\begin{array}{l}\cdots \\
\cdots\end{array}$ & $\begin{array}{l}\cdots \\
\cdots \\
\cdots\end{array}$ & $\begin{array}{l}123 \\
116 \\
232\end{array}$ & $\begin{array}{l}12 \cdot 4 \\
12.5 \\
11 \cdot 2\end{array}$ & $\begin{array}{l}11 \cdot 3 \\
11 \cdot 4 \\
10 \cdot 5\end{array}$ & $\begin{array}{l}6 \cdot 5 \\
6 \cdot 8 \\
6 \cdot 4\end{array}$ \\
\hline $\begin{array}{c}15+\quad \text { years } \\
5-14 " \\
0-4\end{array}$ & $\begin{array}{l}\ldots \\
\cdots\end{array}$ & $\begin{array}{l}\cdots \\
\therefore \\
\cdots\end{array}$ & $\begin{array}{r}263 \\
123 \\
85\end{array}$ & $\begin{array}{l}12 \cdot 1 \\
12 \cdot 0 \\
10 \cdot 8\end{array}$ & $\begin{array}{l}10 \cdot 8 \\
10 \cdot 7 \\
11 \cdot 7\end{array}$ & $\begin{array}{l}6 \cdot 6 \\
6 \cdot 8 \\
6 \cdot 1\end{array}$ \\
\hline
\end{tabular}

Tabulations of $\mathrm{N}$. against $\mathrm{E}$. were also prepared so as to study the combinations of neuroticism and introversion for each diagnostic category (Fig. 1). The results are arranged around the joint means of $\mathrm{E}$. and $\mathrm{N}$. for normal subjects: for normals, $25 \%$ of the sample would be expected to fall in each 
quadrant, but there is clearly an excess in the "unstable introvert" quadrant, for all groups of patients, and particularly for the bronchitics.

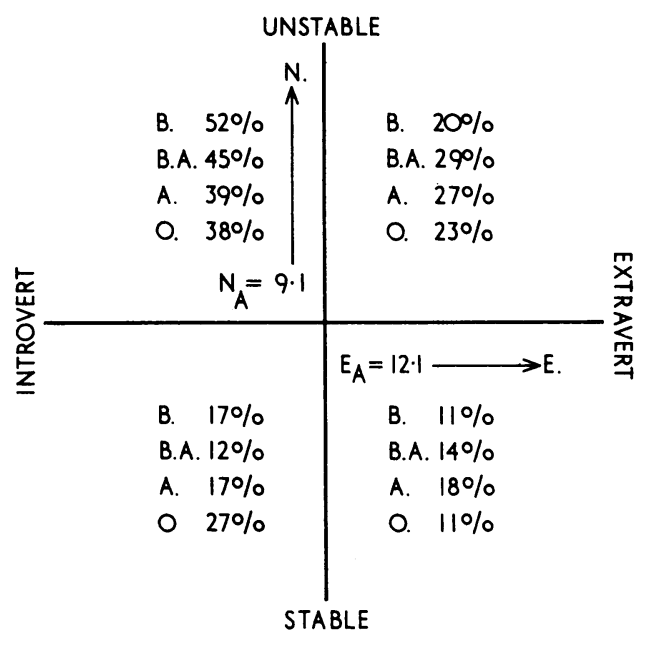

FIG. 1.-Distribution of E. and N. about normal population values.

Throughout these tabulations it is clear that Eysenck's $\mathrm{N}$. score follows the same trends as Cattell's sten score and that neither N. nor sten is related to E. Fig. 2 shows an association between $N$. and sten scores and a lack of association between E. scores or lie scores and sten scores. The correlation coefficient between $N$. and sten scores for the whole series of 471 patients is 0.79 . The lie score is constant over the middle range of $\mathrm{N}$. and sten, but varies inversely with them at the extreme ends of the range; this feature has been observed before (Gibson, 1962) and has been attributed to the concern of some subjects with the image that they might convey of themselves to others.

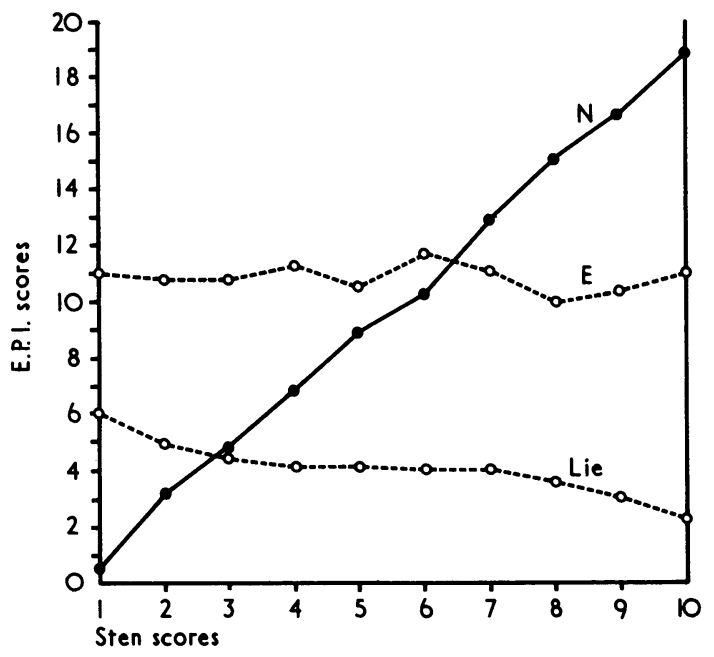

FIG. 2.-Relationship between Eysenck scores and sten scores.

\section{Discussion}

The tables indicate that asthmatic and bronchitic patients have higher mean ratings for neuroticism and anxiety than the general population. This is to be expected in a group of patients most of whom had a moderate or severe chronic disability. The main factor affecting the scores within this group appeared to be the degree of breathlessness; this was of greater importance than the diagnosis of bronchitis and asthma based on a history of cough, phlegm, and attacks of wheezing. The patients with asthma only (A.) suffered from dyspnoea only intermittently, and their $\mathrm{N}$. and sten scores were not quite as high as those with bronchitis only (B.). Perhaps the tendency for dyspnoea in bronchitis to be sustained, and often to have serious socio-economic consequences, contributed to the higher personality ratings.

The steady rise in neuroticism and anxiety in each diagnostic category with increasing breathlessness poses problems in the selection of suitable controls. From the rather scanty information available on comparable systemic disorders, it seems that neuroticism and anxiety increase with the duration and severity of the disability. To this extent, asthma and bronchitis are likely to conform to pattern.

Throughout the study, neuroticism (N.) and anxiety (sten) ratings have shown similar trends, suggesting that they are measuring similar personality traits. Indeed this is likely to be so. There is clearly a continuum from normality to gross neuroticism, the latter having anxiety and other symptoms under minor degrees of stress which a normal person would develop only under much greater stress. These questionaries are thus measures of both normal and abnormal anxiety, and it is impossible to determine the extent to which the abnormally high scores are due to neurotic disposition and how much to normal anxiety in response to respiratory distress and the complications this causes in everyday life. The fact, however, that bronchitics, who no one has previously suggested as being a neurotic group of patients, score highly on both tests suggests that normal anxiety in response to respiratory distress may also be the major factor in asthmatics, in whom a heightening of anxiety with increased respiratory distress would be expected.

About one in five of the patients had abnormally high ratings for neuroticism (N.) and anxiety (sten). These figures, which are to be expected in a group of moderately and severely disabled patients, are reminders of the importance of personality in determining the course and severity of disease. Both traits can aggravate symptoms and may even contribute to a vicious circle between organic and psychological features. In the present context the liability to attacks of reversible airways obstruction or asthma is an added complication. Maybe physicians who treat bronchitic and asthmatic patients should pay rather more attention than they do at present to possible psychological factors, some of which can now be measured reliably by questionaries which can be completed in 5 to 10 minutes. As yet, few physicians are conditioned to applying such tests and very few outpatient departments in general hospitals are suitable places for patients to sit down and complete the forms without undue distraction. It is, however, difficult to escape the fact that many patients with bronchitis and asthma have abnormally high ratings for neuroticism and anxiety. If the information were available for individual patients, those with high ratings would be singled out for special assessment and management of possible emotional and socio-economic aspects. Maybe a trial comparison between Eysenck's and Cattell's scores and clinical impressions would be an informative exercise.

Our thanks are due to Drs. D. Foskett, E. G. Sita-Lumsden, D. Pugh, G. F. Edwards, and M. C. Jones for allowing patients unciar their care to be included in the series and for their assistance in the completion of many of the forms. Professors P. J. Lawther, W. Linford Rees, and J. G. Scadding are also thanked for their valuable comments. Much of the computation was done at the Centre for Computing and Automation at Imperial College, London.

Cattell, R. B., and Scheier, I. H. (1963). Handbook for the IPAT Anxiety Scale Questionnaire. Illinois.

Cotes, J. E. (1968). Lung Function, 2nd ed. Oxford, Blackwell Scientific

Cotes, J. E. (1968). Lung Function, 2nd ed. Oxford, Blackwell Scientific. Personality Inventory. London, University of London Press.

General Register Office (1961). Classification of Occupations, 1960. London, H.M.S.O.

Gibson, H. B. (1962). Acta Psychologica, 20, 18.

Medical Research Council (1966). Questionnaire on Respiratory Symptoms. London.

Todd, G. F. (1966). Statistics of Smoking in the United Kingdom Research Paper No. 1, 4th ed. London, Tobacco Research Council. 